\title{
Phosphate nephropathy after administration of Bowel PURGATIVE CONTAINING SODIUM PHOSPHATE - A CASE REPORT
}

\author{
Agnieszka Perkowska-Ptasińska ${ }^{1}$, Katarzyna Szewczyk ${ }^{2}$, Anna Skuza ${ }^{2}$, Anna Wasińska- \\ KrawCZyK ${ }^{2}$, Andrzej Rydzewski ${ }^{2,3}$
}

\author{
${ }^{1}$ Department of Nephrology and Transplantation Medicine, Transplantation Institute, Medical University Warsaw, \\ Warsaw, Poland \\ ${ }^{2}$ Department of Nephrology, Transplantology and Internal Medicine, Central Clinical Hospital of the Ministry \\ of Interior, Warsaw, Poland \\ ${ }^{3}$ The Jan Kochanowski University of Humanities and Sciences in Kielce, Kielce, Poland
}

\begin{abstract}
A 65-year-old woman was admitted to the hospital with an elevated serum creatinine concentration associated with leukocyturia and erythrocyturia. Past medical history analysis revealed that four months before current hospitalization she had been subjected to colonoscopy preceded by the administration of oral sodium phosphate solution (OSP) as preparation for this procedure. Kidney biopsy revealed mild chronic tubulo-interstitial inflammation and scarring with prominent cortical tubular calcium phosphate deposits. The diagnosis of phosphate nephropathy, most probably secondary to OSP ingestion was made. During follow-up the renal function remained impaired but stable with eGFR of $25 \mathrm{ml} / \mathrm{min} / 1.73 \mathrm{~m}^{2}$. The patient is currently under the care of the nephrology clinic.
\end{abstract}

Key words: OSP nephrotoxicity, nephrocalcinosis, phosphate nephropathy.

\section{Introduction}

Oral sodium phosphate (OSP) solution is commonly used for colorectal cleansing. In Polish pharmacies it is currently available over the counter under the brand name "Fleet Phospho-soda". However, it should be remembered that administration of this agent may lead to severe, acute electrolyte disturbances which can cause renal failure, especially in patients with pre-existing renal disease $[1,2]$. Although the precise mechanism of renal dysfunction is not known, the microscopic picture indicates that sodium phosphate ingestion may cause an acute tubular injury and nephrocalcinosis, complicated by interstitial inflammation and tubulo-interstitial scarring [3, 4].

\section{Case report}

A 65-year-old female patient was admitted to the Department of Internal Medicine and Nephrology,
Central Clinical Hospital of the Ministry of Interior Affairs, because of an elevated concentration of serum creatinine associated with leukocyturia and erythrocyturia. She had a history of hypertension, coronary heart disease, and several episodes of urinary tract infection. Her medications included ramipril, carvedilol, furosemide and lorazepam. The patient denied the consumption of steroidal anti-inflammatory drugs, diuretics, and vitamin $\mathrm{D}$ or calcium-containing medications.

She had a history of colonoscopy for colorectal cancer screening that was performed four months before admission. As preparation for colonoscopy she had received "Fleet Phospho-soda", an oral phosphate sodium solution. After colonoscopy the patient suffered from recurring, widespread abdominal pain, nausea and vomiting, which remitted spontaneously within a few weeks after the procedure. One month after colonoscopy she was found to have an elevated se- 
rum creatinine concentration of $2.4 \mathrm{mg} / \mathrm{dl}$ and was referred to the nephrology clinic.

On admission the patient's physical examination was unrevealing, except for the blood pressure of 150 over $90 \mathrm{~mm} \mathrm{Hg}$. The electrocardiogram and chest $\mathrm{X}$-ray were normal. Serum creatinine and blood urea nitrogen were elevated to $2.47 \mathrm{mg} / \mathrm{dl}$ (eGFR $20 \mathrm{ml} /$ $\mathrm{min} / 1.73 \mathrm{~m}^{2}$ simplified modification of diet in renal disease (MDRD) equation) and $76 \mathrm{mg} / \mathrm{dl}$ respectively. She had mild anemia with hematocrit of $32.3 \%$, and hemoglobin concentration of $10.6 \mathrm{~g} / \mathrm{l}$. Serum calcium, and phosphorus levels were normal (2.33 $\mathrm{mmol} / \mathrm{l}$, and $3.3 \mathrm{mg} / \mathrm{dl}$ respectively), but there was a modest rise in parathyroid hormone (PTH) blood level to $85.4 \mathrm{pg} / \mathrm{ml}$. The urinary phosphorus excretion was normal, and calcium excretion was slightly reduced. Urinalysis revealed trace proteinuria. Urine sediment contained 6-10 leukocytes and 1-2 erythrocytes per high-power field. The urine culture was sterile. Cystoscopy was unremarkable. Abdominal computed tomography (CT) scan was performed, it revealed both kidneys of normal size, with a slightly reduced cortex layer.

An ultrasound-guided percutaneous kidney biopsy was performed. It showed numerous intratubular spherical calcium-phosphate deposits, mostly in distal and collecting tubules. Additionally a spectrum of lesions typical of acute tubular injury in the form of epithelial edema, vacuolization, and flattening together with tubular lumen distension was seen. The interstitium showed mild chronic inflammation, as well as mild degree of fibrosis and tubular atrophy. Two out of 18 visible glomeruli were globally sclerotic, in another two perihilar tuft sclerotization was seen. Immunomorphological examination was negative for immunoglobulins and complement deposition. Based on the renal biopsy findings and clinical presentation a diagnosis of phosphate nephropathy was made.

No specific treatment was administered. One month after kidney biopsy patient had no complaints, and her serum electrolytes levels were normal. Serum creatinine and serum PTH concentrations were still elevated up to $1.99 \mathrm{mg} / \mathrm{dl}$ and $75 \mathrm{pg} / \mathrm{ml}$ respectively.

\section{Discussion}

\section{Calcium-containing deposits in kidney tissue}

Scant calcifications in tubular and/or interstitial compartments constitute a common, nonspecific finding in renal tissue, of no clinical significance. However the presence of numerous calcifications is an important finding. It may be a hallmark of metabolic disturbances, commonly reflecting renal and/or systemic diseases as well as drug toxicities. The proper interpretation of abundant calcifications demands detailed analysis of their localization and chemical composition. As for localization of deposits, medullary calcifications are typical for medullary sponge kidney, they are also commonly found in previously necrotic parts of papillae in the course of analgesic and diabetic nephropathies. Corticomedullary calcifications are commonly seen in malignancy, hyperparathyroidism, excess vitamin D intake, as well as in sarcoidosis and other granulomatous diseases. Calcifications in this region may also appear in magnesium depletion, hypothyroidism, in decreased urinary citrate concentration, infantile hypercalcemia and in Dent's disease. Cortical calcifications usually occur secondary to diffuse cortical disease, as a complication of cortical necrosis, chronic pyelonephritis or vesicoureteral reflux. Other less common etiologies of cortical calcifications include primary and secondary hyperoxaluria, parenteral calcium administration, calcineurin inhibitor toxicity and methoxyflurane abuse [5].

Traditionally pathologists distinguish dystrophic calcifications that accompany necrosis and "metastatic" calcifications in which calcium salt deposits are seen in non-necrotic areas. The presence of numerous "metastatic" calcifications in renal tissue should direct the diagnostics towards the recognition of oxalate nephropathy or nephrocalcinosis associated with calcium-phosphate deposition.

Calcium-phosphate and calcium-oxalate may be distinguished in light microscopy by their morphology and tinctorial characteristics. In hematoxylin-eosin (HE) stained sections oxalate crystals may be easily overlooked, because they are transparent (Fig. 1). Crystals are mostly rhomboid, and often form cluster or rosette-shape aggregates which are refractile and yellow under polarized light (Fig. 2) and do not react with von Kossa stain. Abundant calcium-oxalate renal deposition is typically seen in hyperoxaluria, both primary (a hereditary enzymatic disorder) and secondary (evolving in the course of ethylene glycol

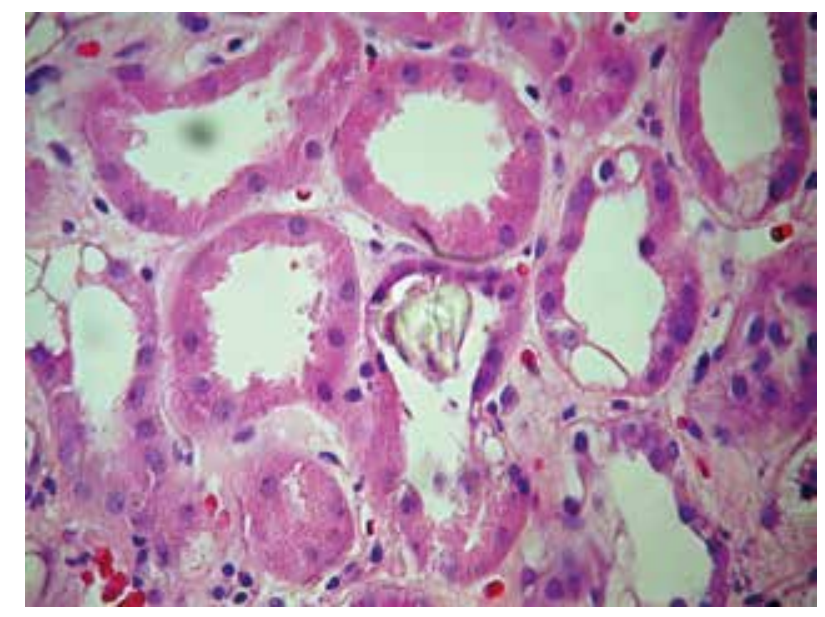

Fig. 1. Calcium oxalate crystals. HE stain. Original magnification $400 \times$ 
poisoning, orlistat toxicity and in disease states associated with malabsorption) [6-9].

Calcium phosphate deposits are typically blue or purple in HE stain, and black in von Kossa stain (Fig. 3). Plentiful of calcium phosphate deposits in renal tissue is a phenomenon that complicates increased renal excretion of calcium and/or phosphate. As for hypercalciuria, it may be idiopathic, but most commonly is related to hypercalcemia that is secondary to primary hyperparathyroidism or malignancy [10-12]. In turn hyperphosphaturia evolves as a result of hyperphosphatemia that is subsequent to excessive phosphate ingestion, massive release of intracellular phosphate, phosphate ingestion in the

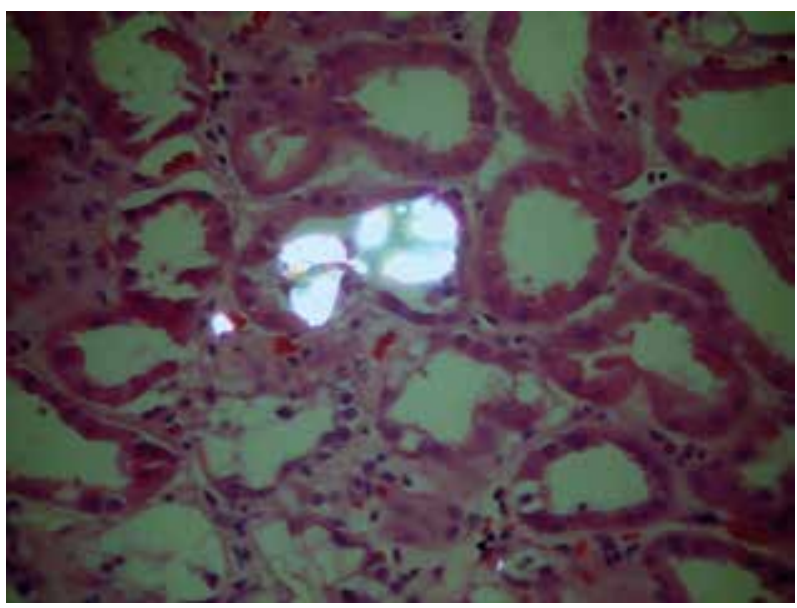

Fig. 2. Calcium oxalate crystals. HE stain, polarization microscopy. Original magnification $400 \times$ setting of impaired gastro-intestinal motility, or renal dysfunction. Hyperphosphaturia may also be secondary to impaired tubular phosphate reabsorption, a phenomenon that complicates nephrotic syndrome (mostly in children), phosphate diabetes, or sodium phosphate solutions intake [13] (Table I presents a list of conditions associated with an increased renal excretion of calcium and/or phosphate).

As documented by Wiech et al., a histopathological appearance of calcium phosphate deposits provides information about the possible etiological background of nephrocalcinosis [19]. In a state of hyperphosphaturia calcifications have typically shelllike and globular structure (Figs. 4, 5), whereas in hy-

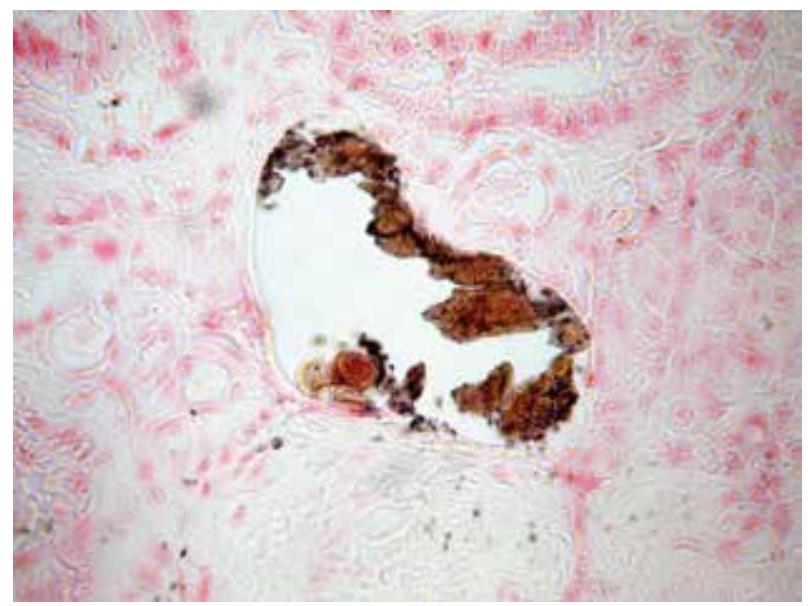

Fig. 3. Calcium oxalate crystals. Von Kossa stain. Original magnification $400 \times$

Table I. Conditions associated with an increased risk of nephrocalcinosis (calcium phosphate renal deposition) $[11,12$, $14,19,24,25]$

\begin{tabular}{ll}
\hline $\begin{array}{l}\text { Hypercalciuria-associated nephrocalcinosis } \\
\text { (clumpy and finely granular deposits homogenously } \\
\text { calcified, not refrictile, black in Von Kossa stain) }\end{array}$ & $\begin{array}{l}\text { Hyperphosphaturia-associated nephrocalcinosis } \\
\text { (shell-like and globular patterns, not refrictile, black in } \\
\text { Von Kossa stain) }\end{array}$ \\
\hline with hypercalcemia & with hyperphosphatemia \\
- hyperparathyroidism & - OSP ingestion \\
- malignancy (osteolytic or humoral type) & - excessive phosphate ingestion over short period of time \\
- vitamin D excess & - massive release of intracellular phosphate \\
- infantile hypercalcemia & - phosphate ingestion in the setting of impaired GI \\
- sarcoidosis and other granulomatous diseases & motility \\
- congenital hypothyroidism & - tumor lysis syndrome \\
- immobilization & - nephrotic syndrome in children \\
\hline without hypercalcemia & without hyperphosphatemia \\
- idiopathic & - phosphate diabetes \\
- Dent's disease & - some inherited tubulopathies \\
- distal (type 1) renal tubular acidosis & - malignancy \\
- medullary sponge kidney & \\
\hline
\end{tabular}




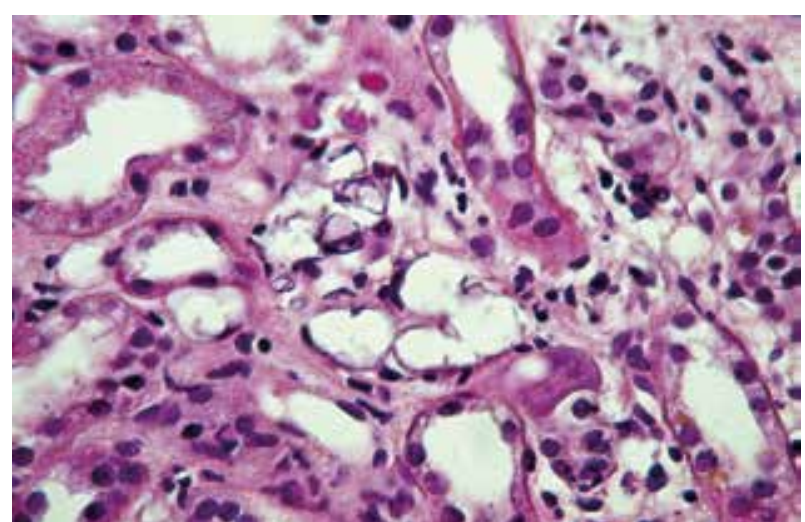

Fig. 4. Calcium phosphate deposits, shell-like pattern. HE stain. Original magnification $400 \times$

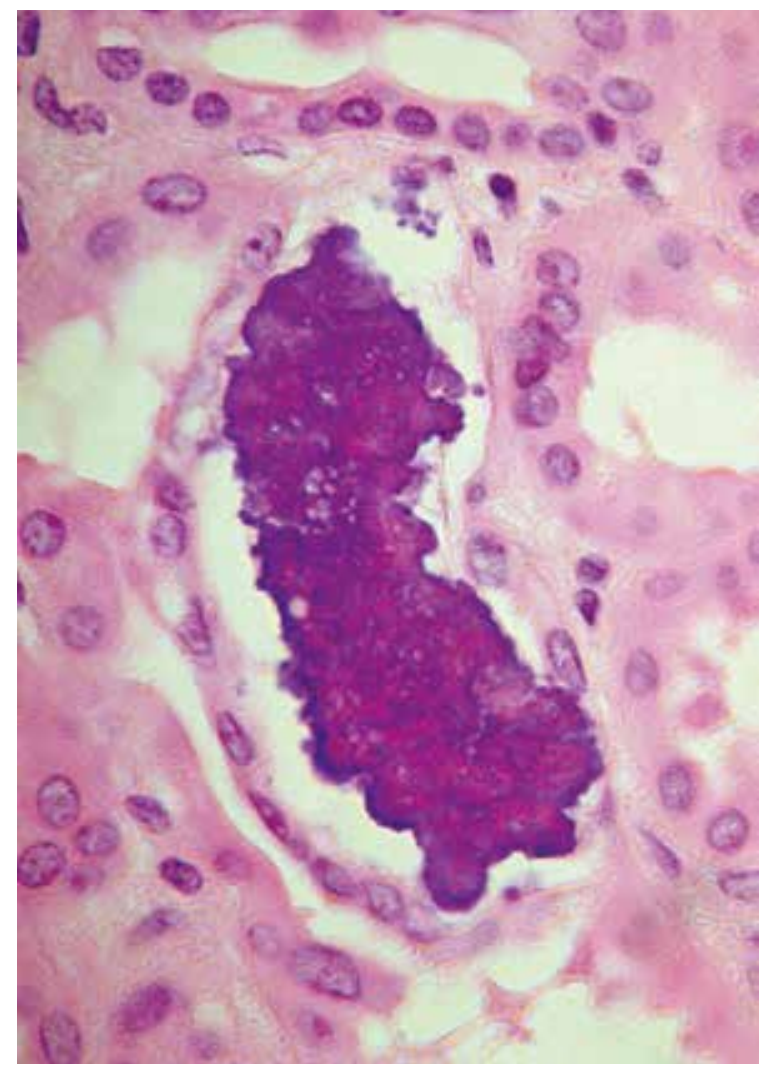

Fig. 6. Calcium phosphate deposits, clumpy pattern. HE stain. Original magnification $400 \times$

percalciuria-associated nephrocalcinosis clumpy and finely granular patterns with homogeneous calcifications predominate (Figs. 6, 7) [19].

Over the last 10 years several reports of renal failure following ingestion of oral sodium phosphate bowel purgatives (OSP) ingestion as a preparation for colonoscopy have been published [3, 4, 14-18]. Oral sodium phosphate preparations are osmotic purgatives that force water excretion into the intestinal lumen. Various complications of OSP ingestion,

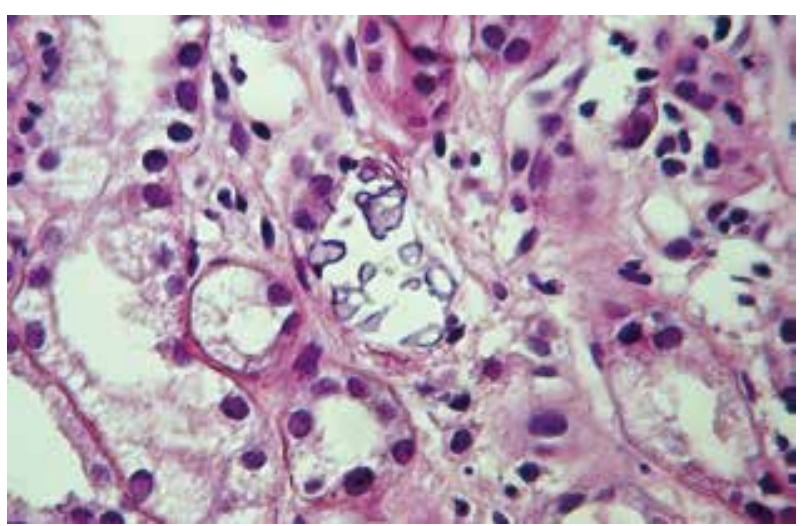

Fig. 5. Calcium phosphate deposits, globular pattern. HE stain. Original magnification $400 \times$

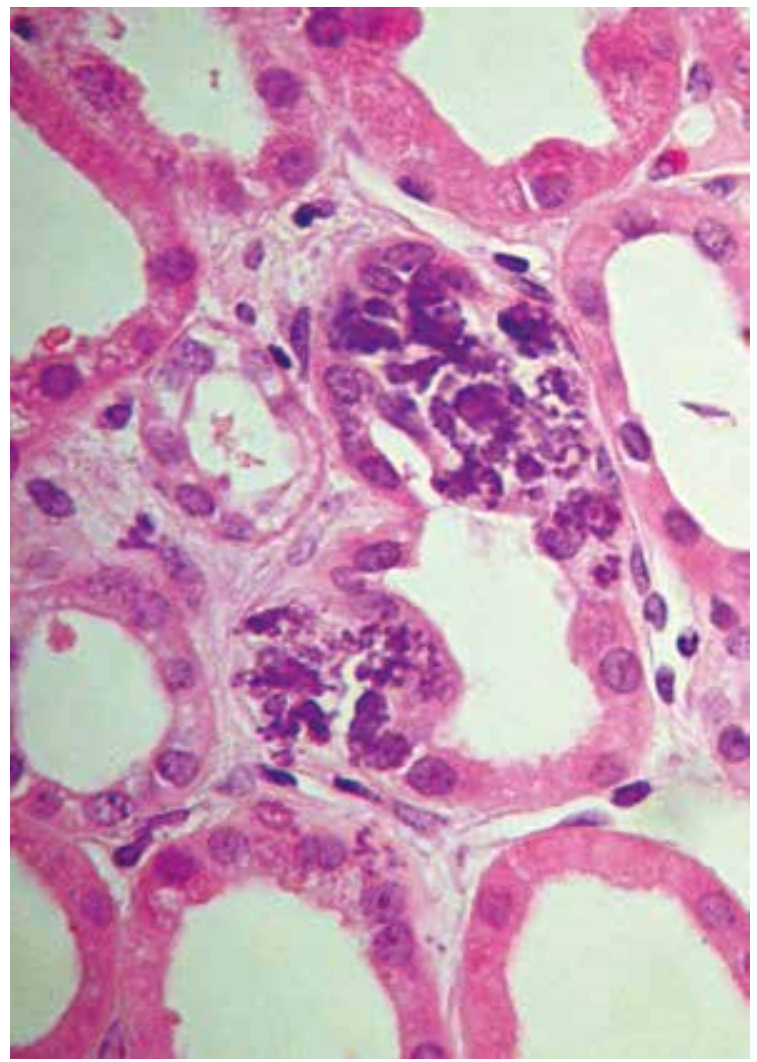

Fig. 7. Calcium phosphate deposits, finely granular pattern. HE stain. Original magnification $400 \times$

including metabolic acidosis, hypernatremia, hyperphosphatemia, hyperphosphaturia, hypocalcemia hypokalemia, have been reported. These electrolyte abnormalities occur within the first few hours after OSP administration, and become particularly severe in patients with slow gastrointestinal transit, pre-existing renal failure, volume depletion, and hyperparathyroidism $[16,18,20]$. Serum calcium and phosphorus levels return do normal within 24 hours, whereas their urinary concentrations remain abnormal much 
longer, especially in patients who received more than one OSP dosage [15].

Sodium phosphate solution ingestion is currently the most common cause of calcium phosphate deposition in renal tissue $[15,19]$. It has been estimated, that the incidence of renal failure after bowel preparation with OSP is $1-4 \%$ in the general population. There are two distinct patterns of OSP related renal failure. One pattern is characterized by an acute renal function deterioration, occurring within few hours or days after OSP administration. With the correction of electrolyte abnormalities this type of renal injury is potentially reversible. In a second pattern renal failure is discovered weeks to months after OSP administration at the time of normal calcium and phosphate blood concentrations, and in most cases is irreversible $[16,17\}$.

\section{Renal biopsy}

The most characteristic lesion of phosphate nephropathy is localized in the renal cortex in the form of calcium phosphate deposits situated in the renal tubular lumen and the cytoplasm of tubular epithelial cells, mostly in distal and collecting tubules, and to a lesser extent in the interstitium. Characteristically these tubular and interstitial deposits are spheroidal, globular, and shell-like, they are blue or purple in HE stain, and black in von Kossa stain. Although typical of phosphate nephropathy these deposits are not fully specific. Similar type of calcifications may also be seen in children with nephrotic syndrome, in phosphate diabetes, as well as in a state of calcineurin inhibitor toxicity $[4,13,15,19]$.

Apart from the presence of renal cortical calcifications within first 3 weeks after the OSP ingestion the microscopic picture is typical of an acute tubular injury that involves all tubular segments, and may be accompanied by mild interstitial edema and inflammation. If the biopsy is performed later on, there is a mixture of acute and chronic lesions in a form of interstitial inflammation (with or without tubulitis) and tubulo-interstitial scarring [21, 22].

Until safer bowel preparation agents are available, the use of OSP in older patients and in those with other risk factors for phosphate nephropathy should be avoided. If OSP is used it has been recommended to ensure adequate fluid intake, to delay and reduce the second dose of OSP or replace it with another agent. Oral sodium phosphate administration should be followed by serum biochemistry tests, in order to detect any renal, or electrolyte abnormalities [23].

\section{Summary}

The use of OSP bowel purgatives may be complicated by transient albeit severe electrolyte abnormalities as well as an evolution of renal failure in an acute reversible, or chronic irreversible form. Oral sodium phosphate related phosphate nephropathy is an important and probably under-appreciated cause of acute and chronic kidney diseases. In patients with unexplained renal failure the physicians should take into account the possibility of distant colonoscopy and investigate what method of preparation was used in the past. The clinical presentation of phosphate nephropathy is unspecific, so the recognition of this entity can only be made on the basis of kidney biopsy microscopic findings. The most characteristic morphological lesion of phosphate nephropathy is the presence of spheroidal, globular and shell-like tubular deposits that are black in von Kossa stain. Characteristically these deposits are accompanied by a mixture of acute and chronic degenerative, inflammatory and fibrotic lesions in tubules and in the cortical interstitium.

\section{Authors declare no conflict of interest.}

\section{References}

1. Beloosesky Y, Grinblat J, Weiss A, et al. Electrolyte disorders following oral sodium phosphate administration for bowel cleansing in elderly patients. Arch Intern Med 2003; 163: 803-808.

2. Patel V, Emmett M, Santa Ana CA, Fordtran JS. Pathogenesis of nephrocalcinosis after sodium phosphate catharsis to prepare for colonoscopy: Intestinal phosphate absorption and its effect on urine mineral and electrolyte excretion. Hum Pathol 2007; 38: 193-194; author reply 194-195.

3. Desmeules S, Bergeron MJ, Isenring P. Acute phosphate nephropathy and renal failure. N Engl J Med 2003; 349: 1006-1007.

4. Gonlusen G, Akgun H, Ertan A, et al. Renal failure and nephrocalcinosis associated with oral sodium phosphate bowel cleansing: clinical patterns and renal biopsy findings. Arch Pathol Lab Med 2006; 130: 101-106.

5. Weiss M, Liapis H, Tomaszewski JE, Arend LJ. Pyelonephritis and other infections, reflux nephropathy, hydronephrosis, and nephrolithiasis. In: Hepinstall's pathology of the kidney. Jennette CJ, Olson JL, Schwartz MM, Silva FG (eds.). $6^{\text {th }}$ ed. Lippincott Williams \& Wilkins, Philadelphia 2007; 992-1083.

6. Harambat J, Fargue S, Bacchetta J, et al. Primary hyperoxaluria. Int J Nephrol 2011; 2011: 864580.

7. Mole DR, Tomson CR, Mortensen N, Winearls CG. Renal complications of jejuno-ileal bypass for obesity. QJM 2001; 94: 69-77.

8. Poldelski V, Johnson A, Wright S, et al. Ethylene glycol-mediated tubular injury: identification of critical metabolites and injury pathways. Am J Kidney Dis 2001; 38: 339-348.

9.Singh A, Sarkar SR, Gaber LW, Perazella MA. Acute oxalate nephropathy associated with orlistat, a gastrointestinal lipase inhibitor. Am J Kidney Dis 2007; 49: 153-157.

10. Beall DP, Henslee HB, Webb HR, Scofield RH. Milk-alkali syndrome: a historical review and description of the modern version of the syndrome. Am J Med Sci 2006; 331: 233-242.

11. Claverie-Martín F, Ramos-Trujillo E, García-Nieto V. Dent's disease: clinical features and molecular basis. Pediatr Nephrol 2011; 26: 693-704.

12. Jacobs TP, Bilezikian JP. Clinical review: Rare causes of hypercalcemia. J Clin Endocrinol Metab 2005; 90: 6316-6322. 
13. Feinstein S, Becker-Cohen R, Rinat C, Frishberg Y. Hyperphosphatemia is prevalent among children with nephrotic syndrome and normal renal function. Pediatr Nephrol 2006; 21: 1406-1412.

14. Heher EC, Thier SO, Rennke H, Humphreys BD. Adverse renal and metabolic effects associated with oral sodium phosphate bowel preparation. Clin J Am Soc Nephrol 2008; 3: 1494-1503.

15. Herlitz LC, D'Agati VD, Markowitz GS. Crystalline nephropathies. Arch Pathol Lab Med 2012; 136: 713-720.

16. Markowitz GS, Whelan J, D'Agati VD. Renal failure following bowel cleansing with a sodium phosphate purgative. Nephrol Dial Transplant 2005; 20: 850-851.

17. Markowitz GS, Perazella MA. Acute phosphate nephropathy. Kidney Int 2009; 76: 1027-1034.

18. Sica DA, Carl D, Zfass AM. Acute phosphate nephropathy - an emerging issue. Am J Gastroenterol 2007; 102: 1844-1847.

19. Wiech T, Hopfer H, Gaspert A, et al. Histopathological patterns of nephrocalcinosis: a phosphate type can be distinguished from a calcium type. Nephrol Dial Transplant 2012; 27: 1122-1131.

20. Ma RC, Chow CC, Yeung VT, et al. Acute renal failure following oral sodium phosphate bowel preparation in diabetes. Diabetes Care 2007; 30: 182-183.

21. Joo WC, Lee SW, Yang DH, et al. A case of biopsy-proven chronic kidney disease on progression from acute phosphate nephropathy. Kidney Res Clin Pract 2012; 31: 124-127.

22. Gumurdulu Y, Serin E, Ozer B, et al. Age as a predictor of hyperphosphatemia after oral phosphosoda administration for colon preparation. J Gastroenterol Hepatol 2004; 19: 68-72.

23. Lien YH. Is bowel preparation before colonoscopy a risky business for the kidney? Nat Clin Pract Nephrol 2008; 4: 606-614

24. Risdon, RA, Woolf, AS. Developmental defects and cystic diseases of the kidney. Heptinstall's pathology of the kidney. $5^{\text {th }}$ ed. Lippincott-Raven, Philadelphia 1998.

25. Wrong OM, Norden AG, Feest TG. Dent's disease; a familial proximal renal tubular syndrome with low-molecular-weight proteinuria, hypercalciuria, nephrocalcinosis, metabolic bone disease, progressive renal failure and a marked male predominance. QJM 1994; 87: 473-493.

\section{Address for correspondence}

\section{Agnieszka Perkowska-Ptasińska}

Department of Transplantation Medicine and Nephrology

Medical University of Warsaw

Nowogrodzka 59

02-006 Warszawa, Poland

e-mail: aggape@poczta.onet.pl 